\title{
Cost and response criteria are the new challenges
}

Jane de Lartigue

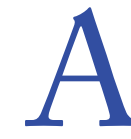

lthough the concept of using immunotherapy to target an immune response against tumors is not new, this treatment modality is only now beginning to realize its full potential. Here, we take a look at the role of immunotherapy in cancer and some of the most exciting areas of clinical development (Figure 1).

\section{The immune system and cancer}

The immune system functions by recognizing signals (antigens) on the surface of invading organisms as "nonself" and mounting a response that ultimately leads to the death of these organisms. Because tumors are made up of our own cells they often don't display these signals and are therefore more or less tolerated by the body. When tumors do display unusual proteins on their surface that could be recognized as nonself, they are able to actively subvert the subsequent immune response. ${ }^{1}$ Indeed, the property of immune evasion has now been added to the list of cancer hallmarks - the key features defined by Weinberg and Hanahan that allow a cell to become malignant. ${ }^{2}$

It has become clear that there are several ways in which tumors achieve a state of immune tolerance. Several of these mechanisms have been targeted for novel therapies and have resulted in the establishment of durable antitumor immune responses that are known as immunotherapies.

\section{Targeting the immune system for cancer therapy}

Most cancer therapies use drugs to directly kill tumor cells, but immunotherapy is a less direct approach that involves finding a way to stimulate a patient's immune system or to use components of the immune system to mount an immune response that will kill tumor cells. This can be done actively, by training the immune system to recognize tumor cells as targets to be destroyed, through the use of a vaccine or by preventing the tumor from suppressing a pre-existing antitumor immune response. Or it can be done passively, bypassing the patient's immune system and directly administering immune effector cells that have been engineered to target the tumor cells. Passive immunotherapy includes the use of monoclonal antibodies and adoptive cell therapy. ${ }^{3}$

\section{Passive immunotherapy}

\section{Monoclonal antibodies}

When the B cells of the immune system encounter a foreign antigen, they rapidly divide to form an army of clones that produce monoclonal antibodies (mAbs). These mAbs bind to their target antigen and initiate a range of immune responses that ultimately lead to the destruction of whatever is displaying the antigen. They have significant therapeutic potential thanks to their ability to seek out and destroy foreign cells, and were famously dubbed "magic bullets" by the German scientist Paul Ehrlich. Indeed, they represent the biggest success story for immunotherapy - the 3 topselling cancer drugs in 2012 were mAbs. ${ }^{4}$

Although mAbs have been labeled as passive immunotherapy, there is mounting evidence that they have an active role in boosting the host antitumor immune response. They function as anticancer agents by targeting cancer cells for destruction by the immune system through antibodydependent cellular cytotoxicity (ADCC) and complement-dependent cytotoxicity (CDC), by inducing programmed cell death, or by blocking key signaling pathways involved in tumor cell growth and proliferation., ${ }^{5,6}$

A major limitation to mAb efficacy is their large size and limited functionality and, as such, researchers are working on ways to improve these. This includes the addition of sugar molecules (glycoengineering), which affects function and antigen binding; the use of smaller antibody fragments, which improves tumor penetration; and the generation of bispecific and trifunctional $\mathrm{mAbs}$, which are able to target multiple antigens and can bind both tumor cells and immune effec- 


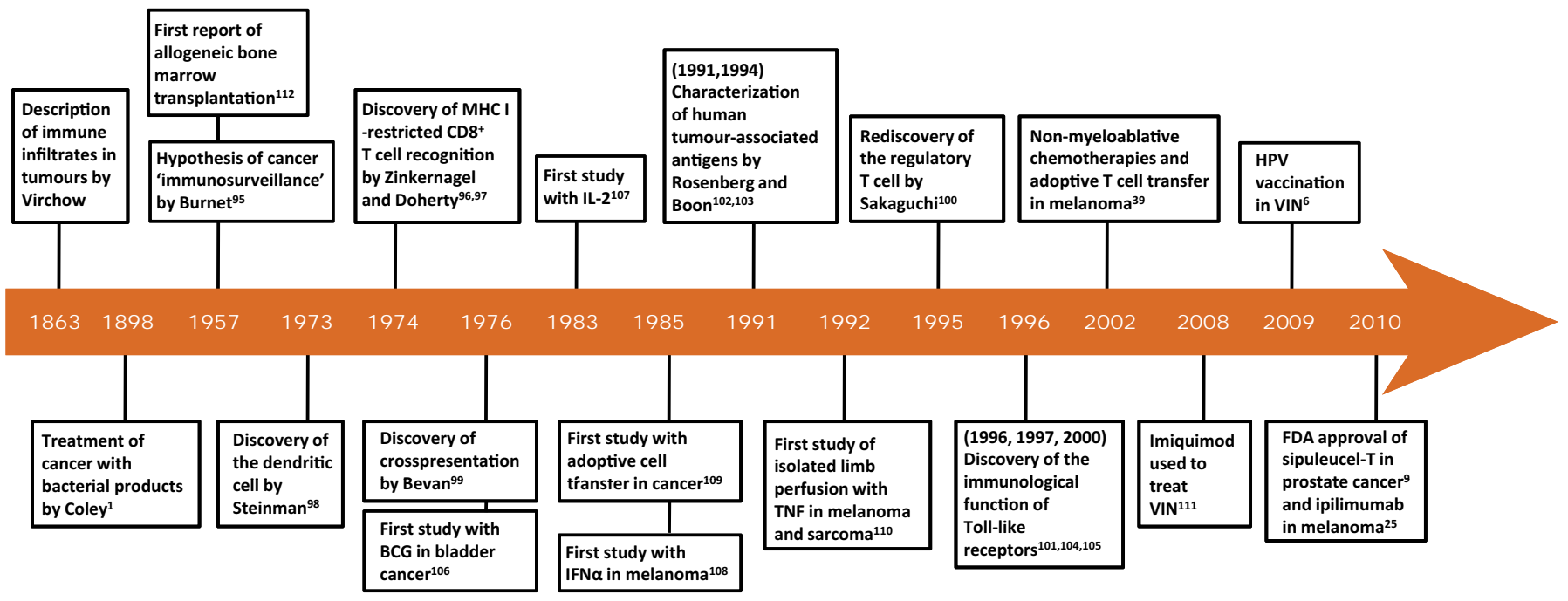

FIGURE 1 A history of cancer immunotherapy, showing immunological discoveries and important clinical trials. ${ }^{10}$

Abbreviations: BCG, bacille Calmette-Guérin; IFN $\alpha$, interferon- $\alpha$; IL-2, interleukin-2; MHC, major histocompatibility complex; TNF, tumour necrosis factor; VIN, vulvar intraepithelial neoplasia.

tor cells simultaneously. The most advanced are conjugated antibodies, in which the antibody is joined to either radioactive chemicals (radioimmunoconjugates), toxins (immunotoxins), or cytotoxic drugs (antibody-drug conjugates). Currently, there are 4 conjugated antibodies that have been approved by the Food and Drug Administration (Table 1).

\section{Adoptive cell therapy}

ACT involves the collection of immune cells (most commonly the $\mathrm{T}$ cells) from a patient, the manipulation of those cells outside of the body (to increase their number or enhance their activity), and then the reinfusion of the cells back into the patient. These immune cells can be collected from the tumor environment (eg, tumorinfiltrating lymphocytes [TILs]) or from the blood supply surrounding the tumor. In the treatment of melanoma, TILs taken from surgically resected tumors, expanded, and then readministered to patients, produced objective responses in $50 \%-70 \%$ of patients and complete regression in $40 \%$ patients. $^{6-9}$

ACT faces a number of drawbacks, including that it is costly and time consuming, and there are also safety issues because patients have to undergo harsh preconditioning regimens to allow the $\mathrm{T}$ cells to survive but that put the patients at risk of opportunistic infections. ${ }^{10}$

$\mathrm{T}$ cells also feature prominently in many of the experimental immunotherapies that are currently being developed. For example, researchers are attempting to reprogram stem cells to act as cancer-targeted T cells, a strategy that has met with significant success in preclinical models.

\section{Active immunotherapy}

The limitation of passive immunotherapy approaches is that they are temporary and don't train the immune system to recognize tumors, which means that patients usually require prolonged or repeated treatment. In addition, they don't address the immunosuppressive mechanisms mounted by the tumor. Active immunotherapies aim to do both of those things.

\section{Vaccines}

Anticancer vaccines represent to many the holy grail of cancer immunotherapy. There are 2 distinct types of cancer vaccine - the prophylactic, which aim to prevent cancers from occurring, and the therapeutic, which aim to treat pre-existing cancers. Preventative vaccination requires identification of the causative agent of a tumor, which is challenging as there may be several causative agents; however, a few preventative vaccines for viralassociated tumors have had significant success, such as the human papillomavirus vaccine that helps prevent cervical cancer. ${ }^{3,7}$ Therapeutic vaccines, have proven much more elusive and a string of failures bred significant skepticism about them. Finally, in 2010, persistence paid off and the first therapeutic vaccine was approved by the FDA: sipuleucel- $T$ for the treatment of metastatic, castrationresistant prostate cancer. Approval was based on the results of the IMPACT (Immunotherapy Prostate Adenocarcinoma Treatment) trial in which the therapy improved overall survival (OS) by 4.1 months and reduced the risk of death by $22 \%$, compared with placebo. ${ }^{6,11}$ 
TABLE 1 Immunotherapies approved by Food and Drug Administration

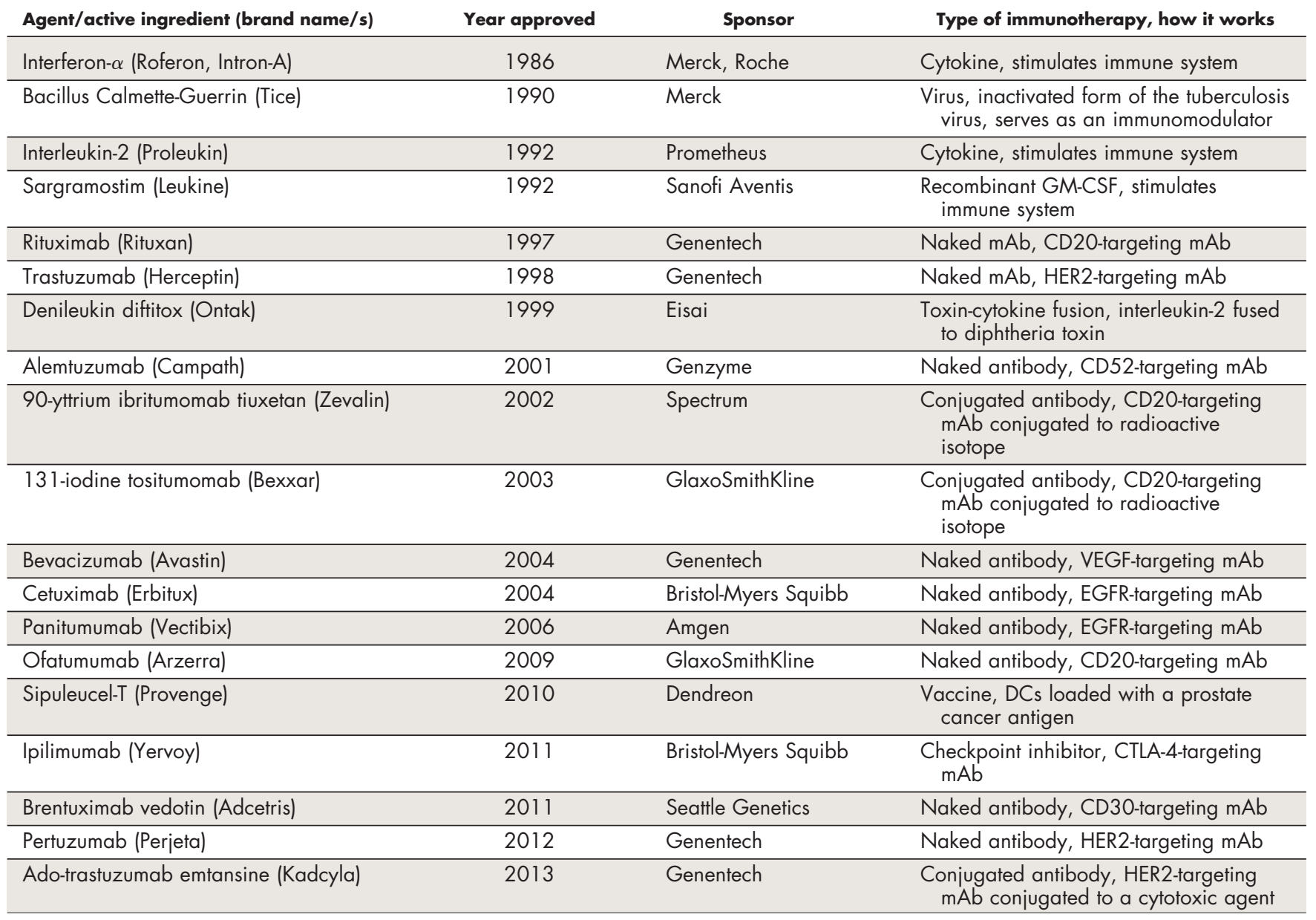

Abbreviations: CTLA-4, cytotoxic T-lymphocyte antigen 4; DCs, dendritic cells; EGFR, epidermal growth factor receptor; GM-CSF, granulocyte macrophage colony-stimulating factor; HER2, human epidermal growth factor receptor 2; MAGE-A3, melanoma-associated antigen 3; mAb, monoclonal antibody; VEGF, vascular endothelial growth factor.

Therapeutic vaccines are designed to immunize a patient against a specific target antigen expressed on the surface of cancer cells (Figure 2). The antigen is delivered using a vector; most commonly a viral vector is used, but dendritic cell (DC)-based vaccines that use DCs to present antigens to immune effector cells are also being evaluated. Other common strategies include peptide vaccines, which use short amino acid stretches of the target protein antigen and are easier to produce. ${ }^{1}$ Messenger RNAbased vaccines are also in the clinic for treatment of prostate and lung cancer (phase 1/2; NCT01915524, NCT01817738) and have the advantage of not requiring a vehicle for delivery to cells and may prove safer because they don't contain viral elements. Researchers are also investigating the potential of stem-cell based vaccines, which target the rapidly proliferating progenitor cells from which tumors develop. ${ }^{6-8}$ A range of vaccines are in late-stage clinical testing in a host of different cancer types (Table 2).

\section{Checkpoint inhibition}

In many cases, an antitumor immune response is mounted and immune cells are found within the tumor and its microenvironment, yet tumor growth persists. Researchers are thus investing significant time and resources in understanding how tumors are able to fly under the radar of this established immune response. It is in this area that one of the most significant recent discoveries in the field of cancer immunotherapy has been made: the discovery of immune checkpoints.

Checkpoint proteins essentially function as the on-off switch on cytotoxic $T$ cells (the killing cells of the immune system). Switching these cells on and off is a 2-step process that requires the interaction of the $\mathrm{T}$-cell receptor 


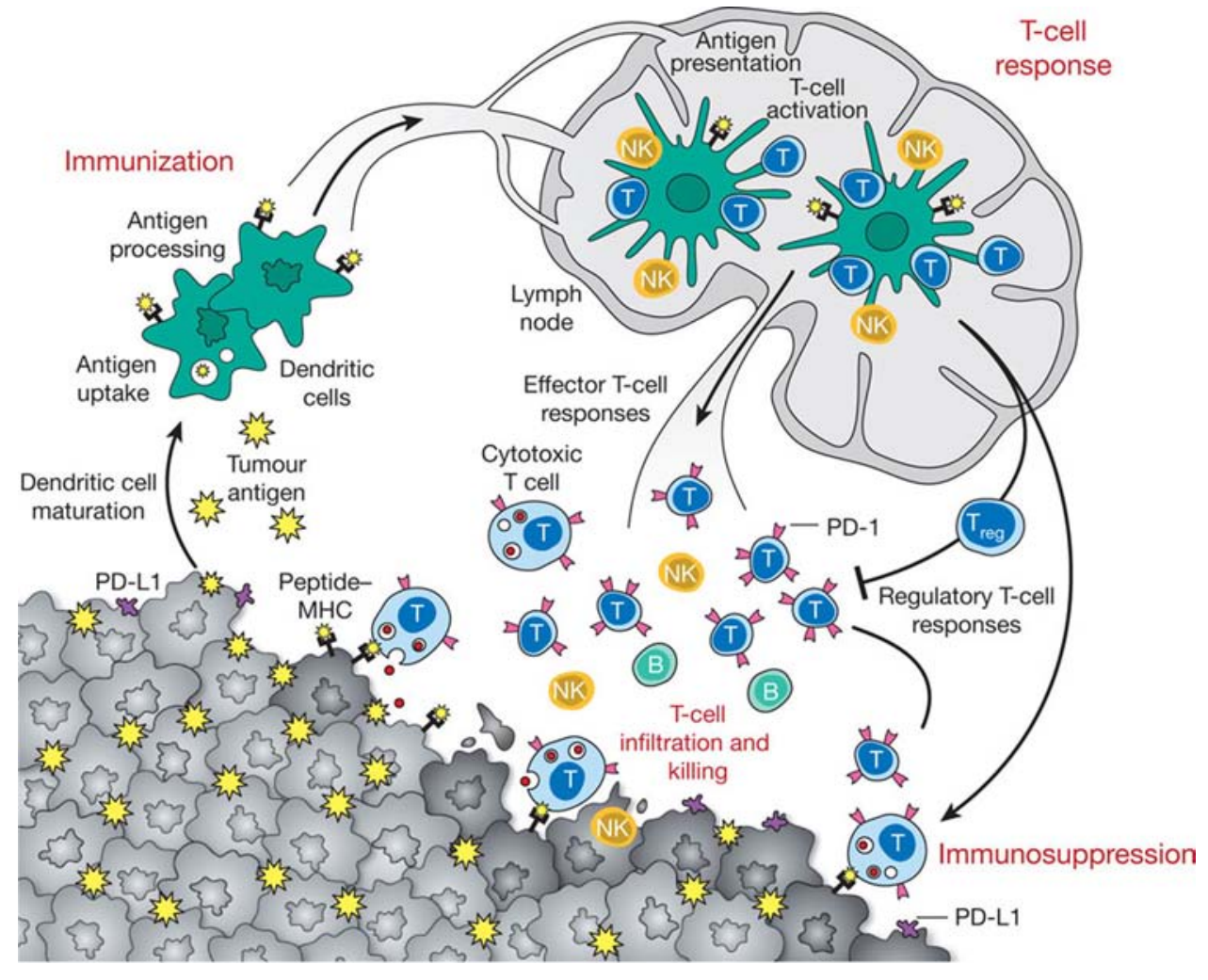

FIGURE 2 Generation and regulation of antitumor immunity. ${ }^{3}$

Abbreviations: MHC, major histocompatibility complex; PD-1, programmed death protein 1. ment, the most advanced being nivolumab (BMS-936558). Others include pidlizumab, lambrolizumab, BMS-936559, MPDL3280A, and AMP-224, which are all in phase 1 or 2 trials in a variety of tumor types.

The metabolic enzyme indoleamine $(2,3)$-deoxygenase (IDO) is a different kind of checkpoint protein. It modulates T-cell activity by depleting the amino acid tryptophan that is essential for T-cell function. It has been found to be overexpressed by both tumor cells and tumorinfiltrating T cells. Several IDO inhibitors are in clinical trials, including indoximod (NewLink Genetics Corporation), in phase 2 trials of metastatic breast cancer (NCT01792050) and refractory metastatic prostate cancer in combination with sipuleucel-T (NCT01560923).

\section{Challenges for the future}

Nine hurdles facing the development of immunotherapy were recently outlined (Table 3). ${ }^{14}$ Among the most significant are cost and with a target cell, and then a secondary signal that determines if the $\mathrm{T}$ cell will be switched on or off. The checkpoint proteins are responsible for this secondary signal (called a coregulatory signal) and thus can be either stimulatory or inhibitory. It was discovered that one of the main ways in which cancer cells suppress the antitumor immune response is by hijacking the checkpoint proteins - ramping up production of inhibitory molecules and suppressing production of stimulatory molecules thus allowing them to effectively switch off cytotoxic $\mathrm{T}$ cells. ${ }^{6,8,12}$

The checkpoint protein that has garnered the most attention is cytotoxic T lymphocyte antigen-4 (CTLA-4) and an antibody targeting CTLA-4, ipilimumab, was approved by the FDA in 2011 for the treatment of melanoma. Clinical trials demonstrated that $45 \%$ of patients treated with ipilimumab are alive after 1 year, 24\% after 2 years, and some patients experienced durable clinical benefit that lasted longer than 4.5 years. ${ }^{13}$

A number of other checkpoint proteins are also being examined. The programmed death $1(\mathrm{PD}-1)$ receptor and its ligands PD-L1 and PD-L2 are part of the same family of coregulatory molecules as CTLA-4. A number of PD-1 and PD-L1/L2-targeting agents are in clinical develop- lack of appropriate measurements of response. Cost is an issue both in the development of immunotherapies, which require a significant financial investment, and in administration of the final product. A complete treatment course of ipilimumab, for example, which consists of 4 infusions over a 3-month period, costs $\$ 120,000$, and the cancer vaccine sipuleucel- $T$ costs $\$ 93,000$ for 3 infusions.

Oncologists typically evaluate a patient's response to cancer therapy by measuring the tumor area or volume using criteria such as RECIST (Response Evaluation Criteria in Solid Tumors) and modified World Health Organization criteria. However, although effective traditional therapies rapidly result in a reduction in tumor size, immunotherapies often have a delayed response, which may follow a period of apparent tumor growth (eg, 10\%-20\% of patients taking ipilimumab show an increase in tumor size after 3 months of treatment but subsequently go on to achieve tumor regression). As such, a challenge to the development of immunotherapy has been the need to develop alternative response criteria. ${ }^{1,10}$

Truly unlocking the full potential of immunotherapy will likely require combination regimens between multiple different types of immunotherapy or between immuno- 
TABLE 2 Late-stage clinical trials in immunotherapies, as of 2013

\begin{tabular}{|c|c|c|c|}
\hline Agent & Trial phase, cancer type, trial number & Manufacturer & Type of immunotherapy, how it works \\
\hline AGS-003 (Arcelis) & Phase 3, metastatic RCC, NCT01582672 & Argos Therapeutics & $\begin{array}{l}\text { DC therapy, DCs loaded with patients } \\
\text { messenger RNA }\end{array}$ \\
\hline $\begin{array}{l}\text { Algenpantucel } \\
\text { (HyperAcute) }\end{array}$ & Phase 3, pancreatic, NCT01072981 & NewLink Genetics & $\begin{array}{l}\text { Vaccine, irradiated live combination of } 2 \\
\text { human pancreatic cell lines that express } \\
\text { the mouse enzyme } \alpha-1,3 \text {-galactosyl } \\
\text { transferase }\end{array}$ \\
\hline Allovectin-7 & Phase 3, melanoma, NCT00395070 & Vical/AnGes MC & $\begin{array}{l}\text { Gene therapy, plasmid/lipid complex } \\
\text { containing DNA encoding HLA-B7 and } \\
\beta 2 \text {-microgluobulin }\end{array}$ \\
\hline Biovax ID & Phase 3, NHL, NCT00091676 & $\begin{array}{l}\text { Biovest } \\
\text { International/ } \\
\text { National Cancer } \\
\text { Institute }\end{array}$ & $\begin{array}{l}\text { Vaccine, hybridoma-derived idiotype } \\
\text { (B-cell antigen) vaccine, made from } \\
\text { patients' tumor cells }\end{array}$ \\
\hline IMA901 & Phase 3, RCC, NCTO1265901 & $\begin{array}{l}\text { Immatics } \\
\text { Biotechnologies }\end{array}$ & $\begin{array}{l}\text { Vaccine, combination of multiple different } \\
\text { tumor-associated peptides }\end{array}$ \\
\hline Multikine & $\begin{array}{l}\text { Phase 3, advanced head \& neck, } \\
\text { NCTO } 1265849\end{array}$ & $\begin{array}{l}\text { CEL-SCl/Teva/Orient } \\
\text { Europharma }\end{array}$ & $\begin{array}{l}\text { Combination immunotherapy, combines } \\
\text { passive and active immune components; } \\
\text { mixture of cytokines including } \\
\text { interleukins, interferons, and chemokines }\end{array}$ \\
\hline Neuvax & Phase 3, breast, NCTO1479244 & Galena Biopharma & $\begin{array}{l}\text { Vaccine, peptide derived from HER2 } \\
\text { combined with GM-CSF }\end{array}$ \\
\hline PROSTVAC & Phase 3, prostate, NCT01322490 & Bavarian Nordic & $\begin{array}{l}\text { Vaccine, sequentially dosed combination } \\
\text { of Vaccinia and Fowlpox poxviruses } \\
\text { that encode prostate-specific antigen } \\
\text { and costimulatory molecules }\end{array}$ \\
\hline $\begin{array}{l}\text { Nivolumab } \\
\text { (BMS-936558) }\end{array}$ & $\begin{array}{l}\text { Phase 3; advanced melanoma, metastatic } \\
\text { RCC, metastatic NSCLC; NCT01844505, } \\
\text { NCT01668784, NCT01673867 }\end{array}$ & $\begin{array}{l}\text { Bristol-Myers } \\
\text { Squibb }\end{array}$ & $\begin{array}{l}\text { Checkpoint inhibitor, mAb targeting PD-1 } \\
\text { protein }\end{array}$ \\
\hline Tremelimumab & $\begin{array}{l}\text { Phase } 3 \text {; advanced melanoma } \\
\text { (discontinued); ongoing phase } 1 \text { and } 2 \\
\text { trials as combination therapy in } \\
\text { melanoma, prostate cancer; } \\
\text { NCTO0702923, NCTO1103635 }\end{array}$ & Medlmmune/Pfizer & $\begin{array}{l}\text { Checkpoint inhibitor, mAb targeting } \\
\text { CTLA-4 }\end{array}$ \\
\hline Elotuzumab & Phase 3, multiple myeloma, NCT01239797 & $\begin{array}{l}\text { Bristol-Myers } \\
\text { Squibb/Abbott }\end{array}$ & Naked antibody, CD2-targeting $\mathrm{mAb}$ \\
\hline Farletuzumab & Phase 3, ovarian, NCT00849667 & Morphotek & $\begin{array}{l}\text { Naked antibody, folate receptor- } \alpha \text { - } \\
\text { targeting } \mathrm{mAb}\end{array}$ \\
\hline $\begin{array}{l}\text { Inotuzumab } \\
\text { ozogamicin }\end{array}$ & $\begin{array}{l}\text { Phase 3, acute lymphocytic leukemia, } \\
\text { NCTO1564784 }\end{array}$ & Pfizer/UCB & $\begin{array}{l}\text { Conjugated antibody, CD22-targeting } \\
\text { mAb conjugated to a cytotoxic agent }\end{array}$ \\
\hline
\end{tabular}




\begin{tabular}{|c|c|c|c|}
\hline $\begin{array}{l}\text { Naptumomab } \\
\text { estafenatox }\end{array}$ & Phase 3, RCC, NCT00420888 & Active Biotech & $\begin{array}{l}\text { Conjugated antibody, 5T4-targeting mAb } \\
\text { conjugated to the Staphylococcal } \\
\text { enterotoxin } E \text { immunotoxin }\end{array}$ \\
\hline Necitumumab & Phase 3, NSCLC, NCT00981058 & Eli Lilly & Naked antibody, EGFR-targeting $\mathrm{mAb}$ \\
\hline $\begin{array}{l}\text { Obinutuzumab } \\
\text { (GA-101) }\end{array}$ & $\begin{array}{l}\text { Phase 3; hematologic malignancies; } \\
\text { NCTO0981058, NCTO1059630, } \\
\text { NCT01287741 }\end{array}$ & Genentech & Naked antibody, CD20-targeting mAb \\
\hline $\begin{array}{c}\text { Onartuzumab } \\
\text { (MetMab) }\end{array}$ & $\begin{array}{l}\text { Phase 3; NSCLC, gastric; NCT01887886, } \\
\text { NCT01662869 }\end{array}$ & Genentech & $\begin{array}{l}\text { Naked antibody, cMet receptor-targeting } \\
\mathrm{mAb}\end{array}$ \\
\hline Racotumomab & Phase 3, NSCLC, NCTO1460472 & $\begin{array}{l}\text { CIMAB/Laborotorio } \\
\text { Elea SACIF }\end{array}$ & Naked antibody, GM3-targeting mAb \\
\hline Ramucirumab & $\begin{array}{l}\text { Phase 3; gastric, liver, breast, CRC, } \\
\text { NSCLC; NCTO } 1168973, \\
\text { NCTO0703326, NCTO0917384, } \\
\text { NCT01140347, NCT01183780 }\end{array}$ & Eli Lilly & Naked antibody, VEGFR-targeting mAb \\
\hline
\end{tabular}

Abbreviations: CTLA-4, cytotoxic T-lymphocyte antigen 4; DCs, dendritic cells; DFS, disease-free survival; EGFR, epidermal growth factor receptor; GM-CSF, granulocyte macrophage colony-stimulating factor; HER2, human epidermal growth factor receptor 2; IL-2, interleukin 2; MAGE-A3, melanoma-associated antigen 3; mAb, monoclonal antibody; MUC-1, mucin-1; NHL, non-Hodgkin lymphoma; NSCLC, non-small-cell lung cancer; PD-1, programmed-death 1; RCC, renal cell carcinoma; TGF, transforming growth factor; VEGF(R), vascular endothelial growth factor (receptor).

a Interim results expected early 2014, granted orphan drug designation by the Food and Drug Administration.

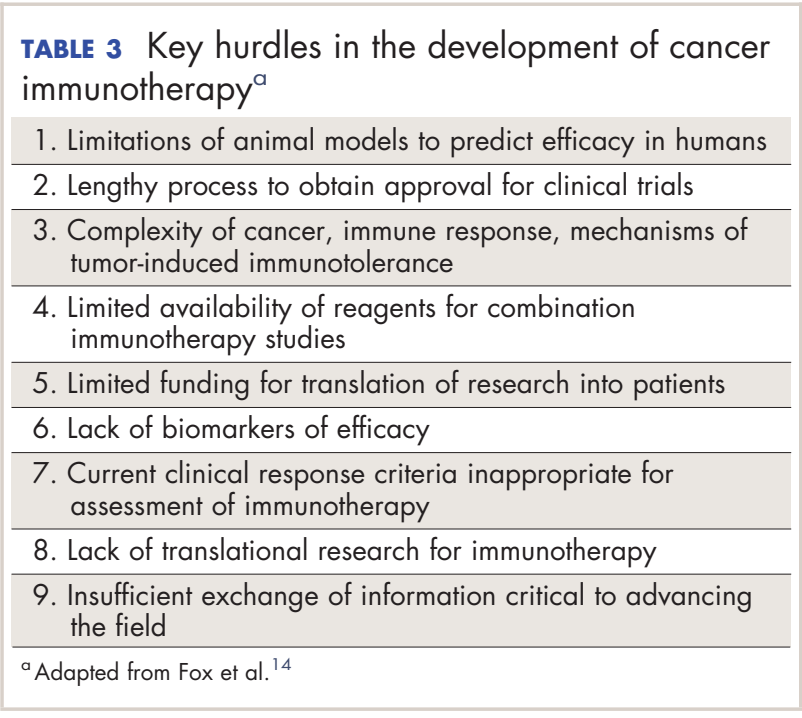

therapies and other treatments such as targeted agents or chemotherapy. This is reflected in the fact that numerous combination studies are already underway. Combinations incorporating immunotherapy have the potential to offer tumor control in both the short- and long-term and provide more durable, long-lasting effects.

\section{References}

1. Kirkwood JM, Butterfield LH, Tarhini AA, et al. Immunotherapy of cancer in 2012. CA Cancer J Clin. 2012; 62:309-335.

2. Hanahan D, Weinberg RA. Hallmarks: the next generation. Cell. 2011;144:646-674.

3. Mellman I, Coukos G, Dranoff G. Cancer immunotherapy comes of age. Nature. 2011;480:480-489.

4. FiercePharma Web site. Top 10 best-selling cancer drugs. http://www. fiercepharma.com/special-reports/top-10-best-selling-cancer-drugs/ top-10-best-selling-cancer-drugs. Posted May 15, 2012.

5. Beck A, Wurch T, Bailly C, et al. Strategies and challenges for the next generation of therapeutic antibodies. Nat Rev Immunol. 2010;10:345-352.

6. Topalian SL, Weiner GJ, Pardoll DM. Cancer immunotherapy comes of age. J Clin Oncol. 2011;29:4828-4836.

7. Dillman O. Cancer immunotherapy. Cancer Biother Radiopharm. 2011;26:1-64

8. Gajewski TF. Cancer immunotherapy. Mol Oncol. 2012;6;242-250.

9. Rosenberg SA. Cell transfer immunotherapy for metastatic solid cancer - what clinicians need to know. Nat Rev Clin Oncol. 2011;8:577-585.

10. Lesterhuis WJ, Haanen JBAG, Punt CJA. Cancer immunotherary revisited. Nat Rev Drug Discov. 2011;10:591-600.

11. Kantoff PW, Higano CS, Shore ND, et al. Sipuleucel-T immunotherapy for castration-resistant prostate cancer. $N$ Engl J Med. 2010;363:411-422.

12. Pardoll D, Drake C. Immunotherapy earns its spot in the ranks of cancer therapy. J Exp Med. 2012;209:201-209.

13. Schwartzenruber DJ, Lawson DH, Richards JM, et al. gp100 peptide vaccine and interleukin-2 in patients with advanced melanoma. N Engl J Med. 2011;364:2119-2227.

14. Fox BA, Schendel DJ, Butterfield LH, et al. Defining the critical hurdles in cancer immunotherapy. J Transl Med. 2011;9:214-228. 